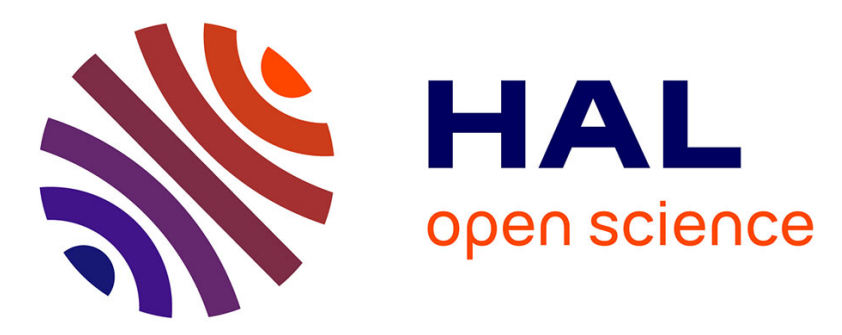

\title{
Ferroelectric Polymer Nanostructures: Fabrication, Structural Characteristics and Performance Under Confinement
}

\author{
D. Guo, F. Zeng, B. Dkhil
}

\section{> To cite this version:}

D. Guo, F. Zeng, B. Dkhil. Ferroelectric Polymer Nanostructures: Fabrication, Structural Characteristics and Performance Under Confinement. Journal of Nanoscience and Nanotechnology, 2014, 14, pp.2086-2100. 10.1166/jnn.2014.9272 . hal-01053228

\section{HAL Id: hal-01053228 \\ https://hal.science/hal-01053228}

Submitted on 24 Nov 2014

HAL is a multi-disciplinary open access archive for the deposit and dissemination of scientific research documents, whether they are published or not. The documents may come from teaching and research institutions in France or abroad, or from public or private research centers.
L'archive ouverte pluridisciplinaire HAL, est destinée au dépôt et à la diffusion de documents scientifiques de niveau recherche, publiés ou non, émanant des établissements d'enseignement et de recherche français ou étrangers, des laboratoires publics ou privés. 


\title{
Ferroelectric Polymer Nanostructures: Fabrication, Structural Characteristics and Performance Under Confinement
}

\author{
Dong Guo ${ }^{1, *}$, Fei Zeng ${ }^{2}$, and Brahim Dkhil ${ }^{3}$ \\ ${ }^{1}$ Institute of Acoustics, Chinese Academy of Sciences, Beijing 100190, China \\ ${ }^{2}$ Department of Materials Science and Engineering, Tsinghua University, Beijing 100086, China \\ ${ }^{3}$ Laboratoire Structures, Propértiés et Modélisation des Solides, Ecole Centrale Paris, CNRS-UMR8580, \\ 92290 Châtenay-Malabry, France
}

\begin{abstract}
Ferroelectric polymers have recently attracted tremendous research interest due to their potential application in various emerging flexible devices. Nanostructured ferroelectric polymer materials, such as nanorods, nanotube, and nanowires, are essential for miniaturization of the relevant electronic components. More importantly, their improved sensitivity and functionality may be used to enhance the performance of existing devices or to develop and design new devices. In this article, the recently developed methods for fabricating ferroelectric polymer nanostructures are briefly reviewed. In particular, the distinct crystallization behaviors confined at the nanometer scale, the nanoconfinement induced structural change, their influence on the physical properties of the ferroelectric polymer nanostructures, and the possible underlying mechanisms are discussed.
\end{abstract}

Keywords: Ferroelectricity, PVDF, P(VDF-TrFE), Nanoconfinement, Polymer Crystallization.

\section{CONTENTS}

1. Introduction . . . . . . . . . . . . . . . . . . . 2086

2. Fabrication of Ferroelectric Polymer Nanostructures . . . . . . 2088

2.1. 'Top-Down' Approaches ... . . . . . . . . . . . . 2088

2.2. Template Synthesis .................... 2088

2.3. Electrospininng and Template Free Self-Organization ... 2091

3. Structural Change and Performance Under Nanoconfinement . . 2092

3.1. Nanoconfinement Effect in Monopolymer PVDF. . . . . . 2093

3.2. Nanoconfinement Effect in Copolymer P(VDF-TrFE) . . . 2093

3.3. Discussion of the Common Features

Under Nanoconfinement. . . . . . . . . . . . . . . . 2095

3.4. Performance of Other Ferroelectric

Polymers Under Nanoconfinement . . . . . . . . . . . . . . . . 2096

4. Influence of Nanoconfinement on the Curie Transition

and Polarization Switching Behaviors . . . . . . . . . . . . . 2097

5. Summary . . . . . . . . . . . . . . . . . . . . . . . . . 2099

Acknowledgments . . . . . . . . . . . . . . . . . . . . . . 2099

References and Notes . . . . . . . . . . . . . . . . . . 2099

\section{INTRODUCTION}

Since the discovery of ferroelectrics by Valasek in 1920, significant theoretical and experimental advances have

*Author to whom correspondence should be addressed. been made in this fascinating field. Owing to the reversible polarization and the strong piezoelectric and pyroelectric effects, ferroelectric materials have been developed for a broad range of applications, including sensing and actuation, ${ }^{1,2}$ data storage, ${ }^{3}$ energy harvesting ${ }^{4,5}$ electrooptics, ${ }^{6,7}$ and electrocalorics. ${ }^{8,9}$ Ferroelectrics may be classified into two major groups: inorganic (oxides and non-oxides) and organic (molecular crystals, liquid crystals and polymers) ones. Inorganic ferroelectrics include a large number of oxides and non-oxides, among which the oxides with the perovskite structure in the form of ceramics are the predominant ones that have been used in various devices. ${ }^{10}$ In comparison, organic materials that display ferroelectric behaviors are mainly limited to a few types of polymers, including monopolymer poly(vinylidene difluoride) (PVDF), some VDF-containing fluorinated copolymers, certain odd-numbered polyamides such as Nylon 7 and Nylon 11,11,12 and blends thereof. ${ }^{13,14}$ Among these ferroelectric polymers, only PVDF and the copolymer of vinylidene fluoride and trifluoroethylene [P(VDF-TrFE)] have been used significantly so far. ${ }^{11}{ }^{15}$ In order to display ferroelectric behaviors, the chains of the ferroelectric 
polymers must be able to crystallize in a manner in which the molecular dipoles do not cancel out. As a result, only the polar $\beta$ and $\gamma$ phases are ferroelectrics. Relative to inorganic ferroelectrics, ferroelectric polymers show low spontaneous polarization, low phase transition temperature (Curie temperature, $T_{c}$ ) and usually a small dielectric constant. However, their special characteristics like high electric breakdown field, light weight, flexibility and ease of processing, etc., make them very promising for specific applications. Particularly, the rapid development of flexible electronics industry in the last two decades has spurred tremendous research interest on ferroelectric polymers.

The ever-increasing demand for device miniaturization requires the fabrication of ordered ferroelectric polymer nanostructures. Compared to inorganic ferroelectrics, ferroelectric polymers show much more complicated structural characteristics such as the many possible configurations and conformations in addition to the partial crystallinity. In the latter, it is generally accepted that the ferroelectricity originates from ordered packing of $\mathrm{F}-\mathrm{C}-\mathrm{H}$ molecular dipoles in the crystalline region. ${ }^{16,17}$
As a consequence, the growth mechanism of ferroelectric polymers crystals is strikingly different from those of inorganic ones, and this in turn leads to their different physical properties. For nanostructured polymers, the situation is further complicated by the confined dimension. ${ }^{18,19}$ Details about the microstructure evolution and size dependent performance of ferroelectric polymers are still not fully understood. $^{20,21}$ On the other hand, unexpected behaviors under geometrical confinement at the nanometer scale (nanoconfinement) may lead to special functionalities that can be used to enhance the performance of existing devices or to develop and design novel devices. ${ }^{22,23}$ Perhaps due to these reasons, nanostructured ferroelectric polymers have been attracting increasing research interest in recent years. There are excellent reviews on organic ferroelectrics ${ }^{15,24}$ and inorganic ferroelectric nanostructures, ${ }^{6,25}$ while a review about the fabrication and performance of ferroelectric polymer nanostructures seems still not available up to now. Here we first provide an overview on the methods developed over the last decade for fabricating ferroelectric polymer nanostructures, mainly those of PVDF
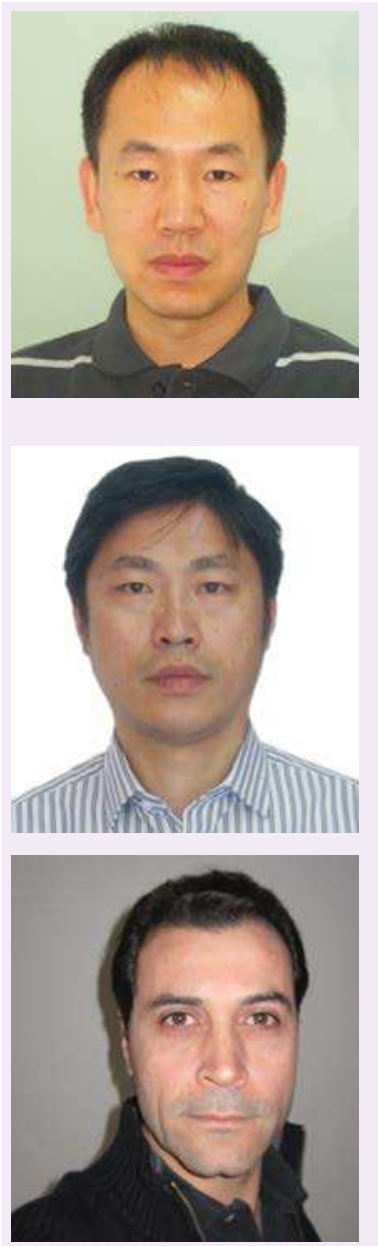

Dong Guo was born in 1974. He received the Ph.D. degree in Department of Materials Science and Engineering in Tsinghua University, Beijing, China, in 2003. From 2003 to 2007, he worked continuously on organic thin films of both small molecules and polymer and relevant devices in Tokyo Institute of Technology (JST postdoctoral researcher), the University of Tokyo (JSPS foreigner postdoctoral researcher), and National Institute for Materials Science (NIMS) in Japan. From 2007 to 2009, he was a foreigner scientist at the Ceramics Laboratory of Swiss Federal Institute of Technology at Lausanne (EPFL). In 2010, he joined in institute of Acoustics, Chinese Academy of Science, as a 'Hundred Talents Program' Professor. He is the leader of the 'Functional Materials Group' of the institute, and the current research of his group is focused on various piezoelectric, ferroelectric and semiconductive materials, and their application in various devices.

Fei Zeng received his Ph.D. degree from Tsinghua University, China, in 2002. He is now an associate professor in School of Materials Science, Tsinghua University, China. His research is focused on the growth of organic and inorganic thin films, their electric properties, and new memory phenomena, such as neuromorphic with simple polymer memory devices. He has published over 100 research articles in the past 10 years.

Brahim Dkhil received a Ph.D. in Materials Science from University of Orsay, France and is currently working at Structures, Properties and Modelling of Solids laborat ory at Ecole Centrale Paris, France. He is the group leader of the "Advanced Ferroics" group aiming at better understanding the microscopic mechanisms and the couplings at the origin of the properties of these materials. His current research focuses on ferroel ectric, relaxor and multiferroic materials and he has over 130 publications. 
and $\mathrm{P}(\mathrm{VDF}-\mathrm{TrFE})$. Following that, we focus the discussion on the nanoconfinement induced structural characteristics and physical property change of the ferroelectric polymers. Furthermore, the possible underlying mechanisms are discussed.

\section{FABRICATION OF FERROELECTRIC POLYMER NANOSTRUCTURES}

There are basically two approaches for fabricating nanostructures: 'bottom-up' and 'top-down.' The former refers to the build-up of nanomaterials starting from the atomic or molecular level. ${ }^{26}$ The latter refers to successive cutting of a bulk material to get ordered arrays of nanostructures by using higher-energy radiation or beams such as laser, $\mathrm{X}$-ray from synchrotron radiation source and focused ion beam, etc. ${ }^{27}$ Both approaches have been used for fabricating ferroelectric polymer nanostructures. In general, the methods are similar to those used for fabricating other types of polymer nanostructures. As the functionality of the ferroelectric polymer originates from the alignment of molecular dipoles in the lager number of connected monomers, molecular packing order and dipole orientation are important factors that need to be considered during processing. ${ }^{16,17}$ The two types of methods will be sequentially discussed in the following Sections 2.1 and 2.2. Some other rarely used methods will also be discussed in Section 2.3.

\section{1. 'Top-Down' Approaches}

\subsubsection{Conventional 'Top-Down' Approaches}

Early work for the fabrication of ferroelectric polymer micro or nanostructures was performed using conventional 'top-down' approaches, and only very few have been reported so far. Nanoscale fabrication of various fluorinated polymers has been demonstrated by direct focused ion beam (FIB) etching without any mask. ${ }^{28}$ The limited data indicated that the etching rates of perfluorinated polymers were about 500-1000 times higher than those of partially fluorinated polymers like PVDF, which was attributed to the limited decomposition of macromolecules because of the formation of network and conjugated double bonds in partially fluorinated polymers. $\mathrm{X}$-rays from a synchrotron radiation source has also been used to photo etch $\mathrm{PVDF}^{29}$ and $\mathrm{P}(\mathrm{VDF}-\mathrm{TrFE})^{30}$ thin films via photodegradation, and polymer patterns in the micrometer scale have been fabricated with a Si membrane mask. However, the need of complicated facilities, the low fabrication rate and the defects or damages caused during processing seriously limit the application of this kind of methods.

\subsubsection{Nanoimprint Lithography}

Nanoimprint lithography (NIL), also referred to as hot embossing, is a simple nanolithography process for fabricating high resolution nanoscale patterns by mechanical deformation of imprint resist and subsequent processing. ${ }^{31,32}$ The imprint resist is typically a monomer or polymer formulation that can be cured by heat or UV light during the imprinting. The imprinting mold is generally prepared by normal nanoprocessing techniques such as electron beam lithography or reactive ion etching. NIL is capable of producing a variety of highly ordered ferroelectric nanostructures. A problem of this method is the difficulty to fabricate nanostructures with high aspect ratio because of the adhesion caused by the high contact area between the mold and the polymer. Surface modification such as self-assembled monolayer and plasma treatment are therefore used for effective release of the polymer nanostructures. ${ }^{33}$

Early work about application of imprinting to fluorinated polymers was conducted to pattern $\alpha$-phase PVDF, which is not a ferroelectric. ${ }^{34}$ Another study indicated that pressure could induce the formation of ferroelectric $\gamma$-phase PVDF. ${ }^{35}$ Imprinting of thin PVDF films with polydimethylsiloxane (PDMS) mold at a pressure of hundreds $\mathrm{kPa}$ at elevated temperatures produced micropatterns in which the regions compressed by the molds were transformed into the ferroelectric phase, while the obtained patterns were in sub-micrometer scale. In contrast to pure PVDF, ferroelectric phase of the copolymer P(VDFTrFE) can be directly formed in many manners. Zhang and coworkers ${ }^{36}$ applied imprinting to P(VDF-TrFE) films, which showed well shaped ferroelectric hysteresis loops, and a good correlation was observed between the remnant polarization and the surface potential of the imprinted films.

A later study demonstrated the possibility to get nanocell arrays (Fig. 1) with preferentially orientated molecular dipoles and significantly eliminated structural defects by using the NIL method with optimized processing conditions. ${ }^{37}$ The improved structure quality enables low-voltage operation and uniform polarization switching. A more recent study developed a rapid nanoimprinting process to pattern large area of $\mathrm{P}(\mathrm{VDF}-\mathrm{TrFE})$ regular arrays with a much shorter imprinting time than the normal NIL procedure. ${ }^{38}$ As shown in Figure 2, the reported smallest feature size of the imprinted pattern is $139 \mathrm{~nm}$. Good ferroelectric properties and piezoresponse for the patterns obtained under the optimal imprinting conditions without annealing treatment have also been achieved.

\subsection{Template Synthesis}

'Template synthesis' is a well established 'bottom-up' approach in fabricating various types of nanostructured materials, and it is also a widely used strategy in making ferroelectric polymer nanostructures. ${ }^{39,40}$ The method consists of two main steps: nanomolding via infiltration of polymer solution or melt into the nanosized channels or poresin a non-reactive template and subsequent removal of the template. One dimensional polymer nanowires, rods and tubes with an inverse geometry of the template can be 

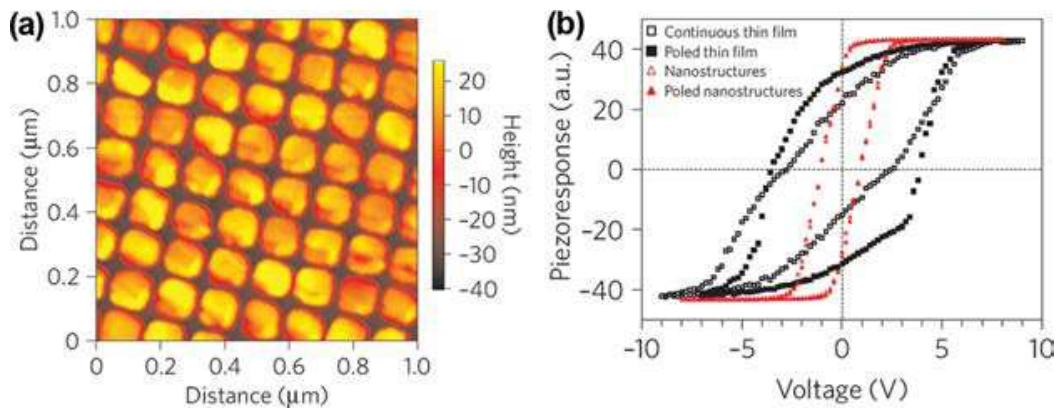

Figure 1. (a) AFM topography image of P(VDF-TrFE) copolymer nanocell arrays; (b) Hysteresis loops of unpoled nano-embossed P(VDF-TrFE) nanostructures (open triangles), of an unpoled similarly annealed P(VDF-TrFE) thin film (open squares) and of the poled nanostructures (filled triangles) and film (filled squares). Adapted with permission from [37], Z. J. Hu, et al., Nat. Mater. 8, 62 (2009). ( ) 2009, Macmillan Publishers Ltd.

formed. The method is advantageous for several reasons: availability of templates in a wide range of sizes from commercial sources, highly ordered nanostructure arrays, controllable size of the products and high fabrication efficiency, etc. In addition, by controlling the processing parameters, such as the type of solvent, solution concentration, evaporation rate and number of infiltration, etc., different nanostructures (e.g., nanowires or hollow nanotubes) can be obtained from the same type of template. A problem of the method is that the removal of the template may affect the nanostructure geometry. Infiltration of polymers into the nanomolds is a crucial step in controlling the morphology of the nanostructures. The infiltration process can be spontaneous via wetting or capillary forces or be carried out by applying an external force, using vacuum-based or rotational methods.

\subsubsection{AAO Template}

Among the available templates, porous Anodic Aluminum Oxide (AAO) is by far the most frequently used one, ${ }^{39,41}$ which allows preparation of ordered arrays of homogeneous nanowires, nanotubes and nanorods, etc., with diameters ranging from 20 to $400 \mathrm{~nm}$ and lengths up to about $300 \mu \mathrm{m}$. AAO template also permits easy release of the nanostructures. In addition, nanostructures can be harvested in large quantities owing to the high pore density of the templates. Because aluminum oxide is an amphoteric material, the AAO templates can be dissolved away with either an acid or a base. As the ferroelectric polymers are acid or base insensitive, they can be easily released from the template.

The AAO template method was first applied to inorganic ferroelectric nanostructures such as $\mathrm{BaTiO}_{3}$ and $\mathrm{PbTiO}_{3}$. In 2003, Steinhart et al. ${ }^{42}$ fabricated PVDF nanotubes with a diameter of around $400 \mathrm{~nm}$ by both melt-wetting and solution wetting of the AAO template. While because the PVDF nanotubes showed a normal non-ferroelectric $\alpha$-phase, the performance were not discussed. By solution wetting of AAO template, Garcia-Gutierrez et al. ${ }^{43}$ fabricated arrays of isolated ferroelectric $\gamma$-type PVDF nanorods connected by a paraelectric $\alpha$-phase supporting film. For the ferroelectric copolymer, Lau and coworkers ${ }^{44}$ fabricated dense $\mathrm{P}(\mathrm{VDF}-\mathrm{TrFE})$ nanowires and nanotubes with diameters ranging from 55 to $360 \mathrm{~nm}$ and a length of about 30 to $55 \mu \mathrm{m}$ by hot pressing a thin layer of solution cast $\mathrm{P}(\mathrm{VDF}-\mathrm{TrFE})$ films into the porous AAO templates and subsequent annealing treatment. It was found that when a template with a pore size of $\sim 60 \mathrm{~nm}$ was used, nanowires with a similar diameter were formed (Figs. 3(a) and (b)), while a larger template pore size of $\sim 200 \mathrm{~nm}$ favored the formation of nanotubes with a larger outer diameter of $\sim 360 \mathrm{~nm}$ and a wall thickness of $\sim 45 \mathrm{~nm}$ (Figs. 3(c) and (d)). A ferroelectricto-paraelectric phase transition is also confirmed for both the nanowires and nanotubes from the temperature dependence of permittivity.

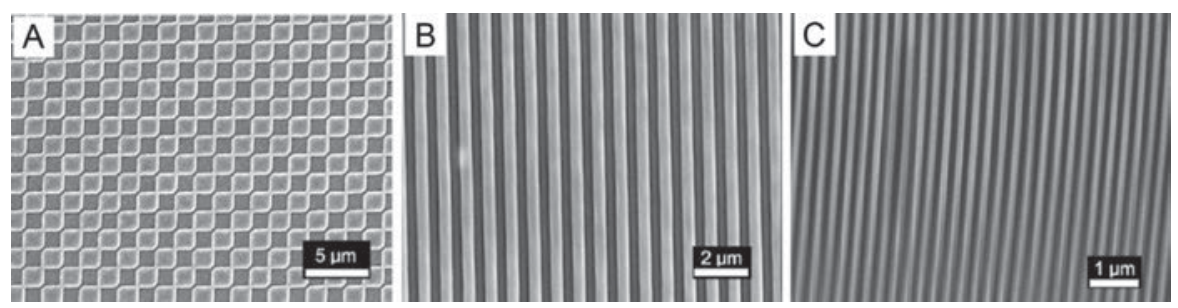

Figure 2. SEM images of patterns imprinted at optimal conditions: (a) two-dimensional square pattern; (b) one dimensional line pattern; (c) onedimensional line pattern with feature size of $139 \mathrm{~nm}$. Reprinted with permission from [38], Y. M. Liu, et al., ACS Nano 4, 83 (2010). (C) 2010, American Chemical Society. 

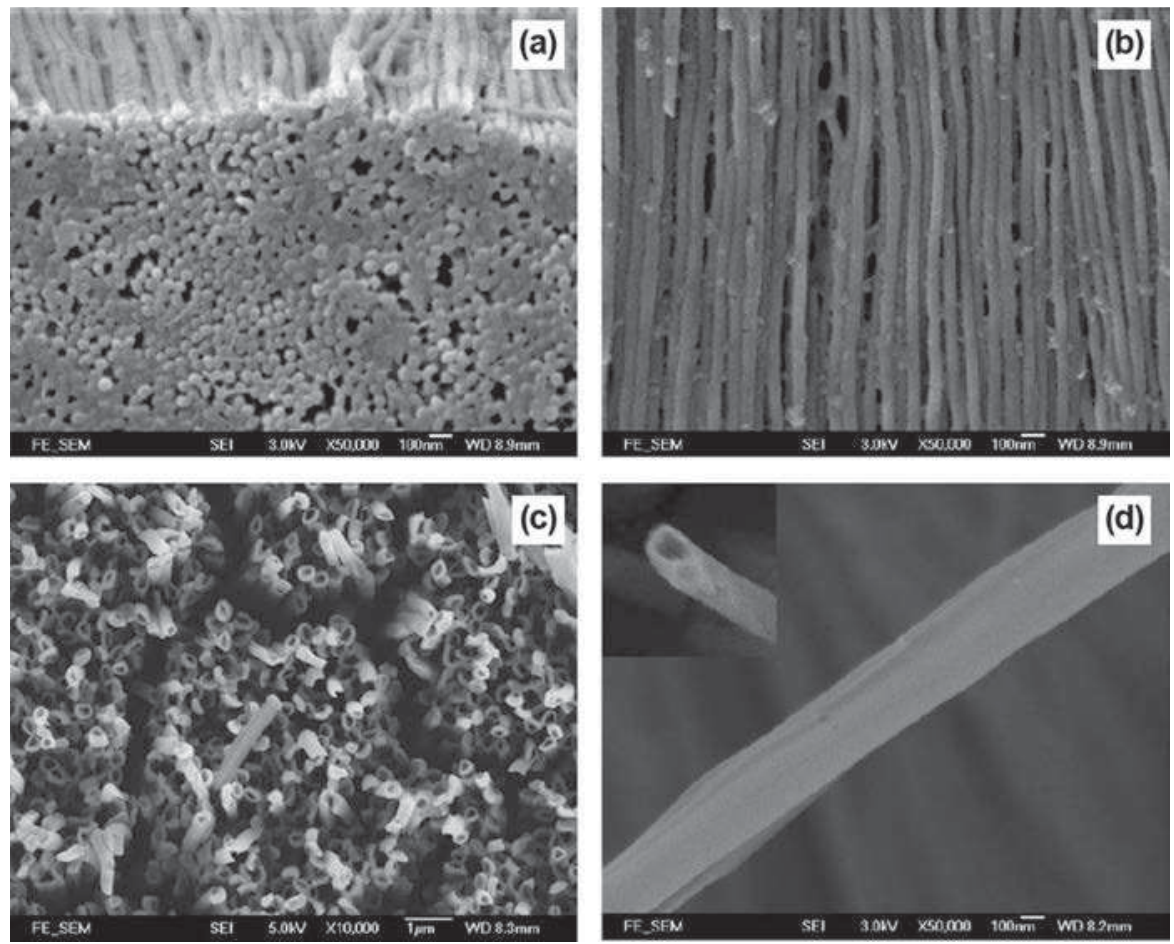

Figure 3. (a) and (b) are the SEM images of the P(VDF-TrFE) nanowires; (c) and (d) are the SEM images of the P(VDF-TrFE) nanotubes. Reprinted with permission from [44], S. T. Lau, et al., Mater. Lett. 60, 2357 (2006). () 2006, Elsevier B.V.

Using the AAO template, $\mathrm{Li}$ et al. ${ }^{45}$ fabricated arrays of special $\mathrm{P}(\mathrm{VDF}-\mathrm{TrFE})$ nanotubes being sealed at one end and linked at the open end. The authors deposited silver electrodes on both the outer and inner sides of the nanotubes by electroless plating. In such a structure, electrical short-circuit between the inner and outer electrodes can be avoided. A much larger capacitance due to the greatly enlarged contact area between the electrodes and the polymer dielectric was reported for the nanotube array. Similar method was also used to fabricate a composite consisting of $\mathrm{P}(\mathrm{VDF}-\mathrm{TrFE})$ nanotubes and an organic semiconductor filler. ${ }^{46}$ The composite showed a large dielectric constant, which was attributed to the significantly enhanced interface polarization between the fillers and the polymer matrix. There are also many other works about fabrication of PVDF or P(VDF-TrFE) nanostructures using the similar template, ${ }^{47-52}$ which will not be discussed in detail here because of the similarity in processing and feature sizes, etc.

\subsubsection{Silicon Based Template}

It was found that the AAO template might cause entanglement and leaning of the nanostructures due to the low stiffness and softness of the polymers. To get well-aligned ferroelectric polymer nanorod arrays, $\mathrm{SiO}_{2}$ templates prepared by a semiconductor fabrication process were also tried. ${ }^{53}$ In this method, after infiltration of $\mathrm{P}(\mathrm{VDF}-\mathrm{TrFE})$ solution into the template, the sample was dried in a vacuum oven at room temperature. The results demonstrated that when the template removal and crystallization of the polymer were carried out simultaneously in hot etchant at around $100{ }^{\circ} \mathrm{C}$, well-aligned arrays of one-dimensional nanorods with a diameter of $\sim 120 \mathrm{~nm}$ with still a high aspect ratio was obtained (Fig. 4). Unlike the AAO templates, however, a problem of this method is that infiltration of $\mathrm{P}(\mathrm{VDF}-\mathrm{TrFE})$ solution can be inhibited due to air in the holes because the bottom of the $\mathrm{SiO}_{2}$ templates is blocked.

A vertically oriented $\mathrm{P}(\mathrm{VDF}-\mathrm{TrFE})$ 'nanograss' structure with a nanopillar diameter around $20 \mathrm{~nm}$ and with still a high aspect ratio has been imprinted using a silicon nanograss mold. ${ }^{54}$ Through evaporation-induced selfassembly of silica-precursor solution in the channels of AAO template, Cauda et al..$^{55}$ synthesized columnar mesoporous silica embedded in AAO membrane templates. Such a structure may be seen as a composite template. By wet-impregnation of the hierarchical host membrane template with PVDF and P(VDF-TrFE) solution and subsequent thermal treatment, the authors fabricated ferroelectric polymer nanowires with a diameter of around 5 to $10 \mathrm{~nm}$ and a length up to $60 \mu \mathrm{m}$ (Fig. 5). These results indicate that $\mathrm{Si}$ based template may be used to fabricate one-dimensional ferroelectric polymer nanostructures with a smaller feature size compared to those made from AAO templates. 
(a)
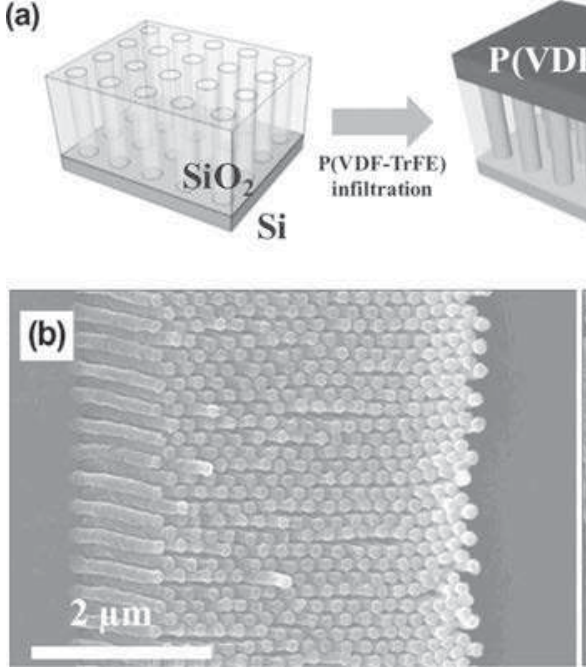

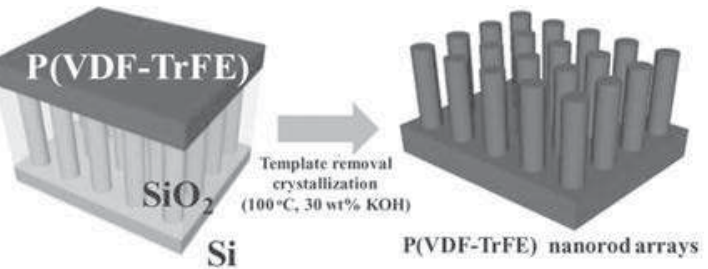

P(VDF-TrFE) nanorod arrays

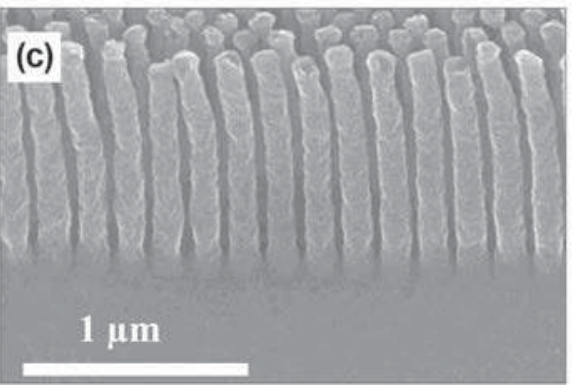

Figure 4. (a) Schematic process diagram of nanostructure fabrication; (b) and (c) are the SEM images of the P(VDF-TrFE) nanorod arrays. Adapted with permission from [53], Oh, et al., Adv. Mater. 24, 5708 (2012). @ 2012, Wiley-VCH Verlag GmbH \& Co. KGaA, Weinheim.

\subsection{Electrospininng and Template Free Self-Organization}

Electrospinning is a highly suitable technique for the fabrication of high aspect ratio polymer nanofibers, despite its difficulties to precisely control the fiber diameter and to achieve diameters bellow $100 \mathrm{~nm} \cdot{ }^{56}$ PVDF usually forms a non-ferroelectric phase, however, ferroelectric PVDF nanofibers have been directly fabricated recently by using
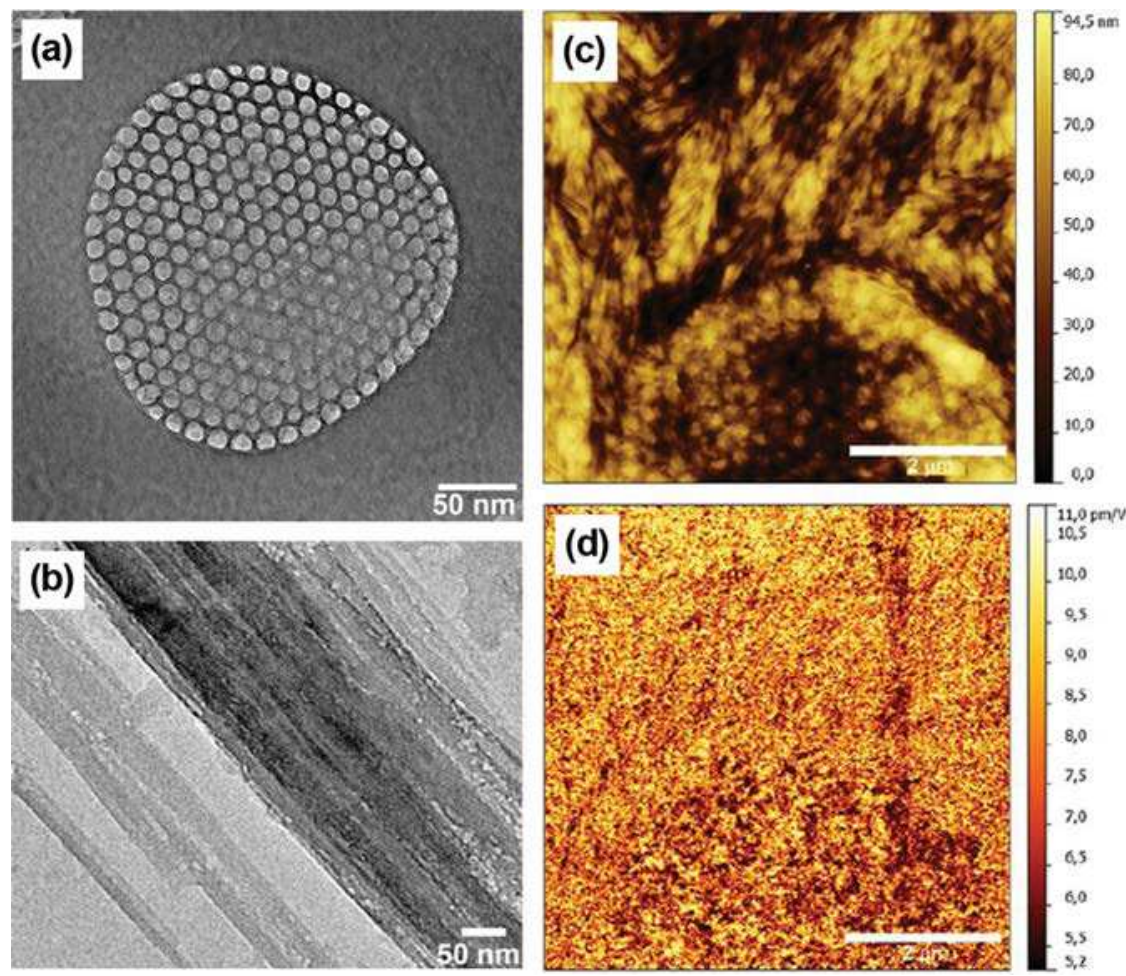

Figure 5. (a) Transmission electron microscopy (TEM) images of the plane-view of columnar mesoporous silica in AAO membranes; (b) PVDF rods in AAO with a pore size of $10 \mathrm{~nm}$; (c) AFM topology image of the array of PVDF nanowires distributed in AAO with a pore size of $10 \mathrm{~nm}$; (d) modulus of the piezoelectric coefficient $d_{33}$ estimated by PFM of the nanowires shown in image (c). Adapted with permission from [55], V. Cauda, et al., Chem. Mater. 240, 4215 (2012). () 2012, American Chemical Society. 
near-field electrospinning, and a novel nanogenerator with interesting mechanical stretch and electrical poling characteristics has been reported. ${ }^{4}$ The strong electric fields and stretching forces result in preferentially oriented dipoles in the nanofiber crystals, and thus the nonpolar $\alpha$-phase structure can be transformed into polar $\beta$-phase one. Moreover, in this method poling is not needed to induce dipole orientation, and the fibers can directly produce voltage and current outputs when the substrate is stretched and released repeatedly (Fig. 6). However, the reported diameters of the as-spun ferroelectric nanofibers fabricated by this way are in the micrometer scale. $\mathrm{P}(\mathrm{VDF}-\mathrm{TrFE})$ nanofiber webs with diameters of about $60-120 \mathrm{~nm}$ have also been prepared by normal electrospinning. ${ }^{57}$ As the dipoles in the nanofibers are preferentially oriented toward the thickness direction of the nanoweb, enhanced performance was considered to be possible by stacking the nanofiber webs.

Among the 'bottom-up' approaches, self-assembly based template free method is one of the simplest routes for preparing nanostructures. ${ }^{26,58-60}$ However, a significant problem is that the material or its precursor must have the intrinsic ability for self-organizing, which is driven by interactions that can minimize the overall energy of the system. ${ }^{61}$ Although self-assembly has been successfully used for the synthesis of some specific organic nanostructures with controllable patterns or geometries, the spectrum of materials that can integrate polymer is still limited, ${ }^{62,63}$ and up to now only very few studies have been tried for ferroelectric polymers. Numerical simulation based on phase field approach indicates that proper external mechanism may trigger the formation of self-organized
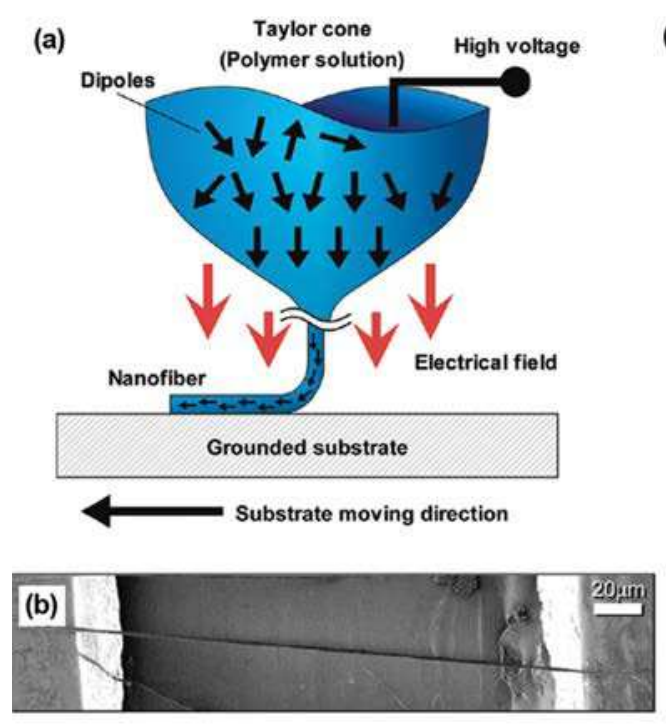

$\mathrm{P}(\mathrm{VDF}-\mathrm{TrFE})$ nanostructure patterns and regulate their size, morphology and distribution. ${ }^{64} \mathrm{~A}$ recent experiment has demonstrated that $\mathrm{P}(\mathrm{VDF}-\mathrm{TrFE})$ nanowire (with a diameter around $200 \mathrm{~nm}$ ) patterns can be fabricated from the melt phase by confined crystallization without any templates. ${ }^{65}$ The large difference in the lateral and vertical amplitude signals of Piezoresponse Force Microscopy (PFM) also reveals an anisotropic piezoelectric response of the nanowires because their dipoles are preferentially orientated parallel relative to the substrate. These studies demonstrate the possibility of fabricating ferroelectric polymer nanostructures via template free self-assembly. However, to fully realize the technological potential of the method, problems like poor control over size and distribution and irregular morphology of the nanostructures need to be resolved.

\section{STRUCTURAL CHANGE AND PERFORMANCE UNDER NANOCONFINEMENT}

Nanostructured materials always show remarkable deviations in properties compared to bulk materials. This is especially true for ferroelectric polymer. The growth or crystallization of polymer is a non-equilibrium process that requires the cooperative movements of large number of connected monomers. ${ }^{66,67}$ In polymer nanostructures the process is further complicated by the constrained geometry, and the resulting crystalline morphologies are usually metastable. On the other hand, reduction in dimension may cause significant change in the long and short range ordering of molecular dipoles, which in turn
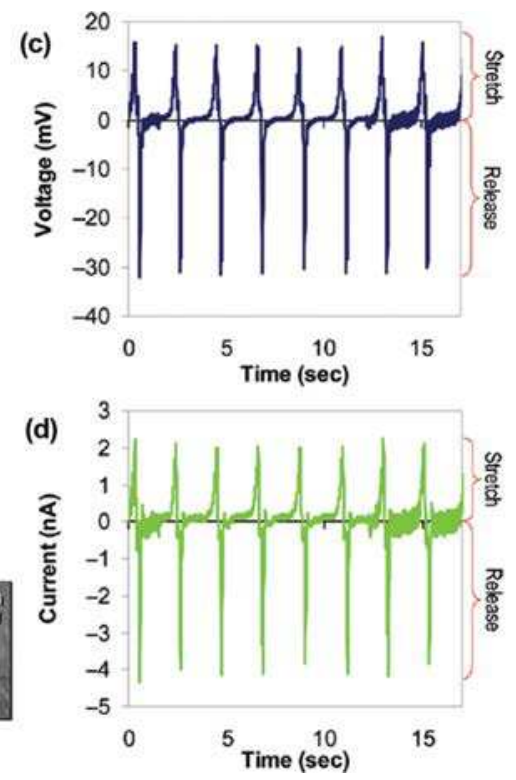

Figure 6. (a) Schematic illustration of the nanogenerator fabrication process that combines near-field electrospinning, direct-writing, mechanical stretching, and in situ electrical poling; (b) SEM image of a single PVDF fiber nanogenerator; (c) and (d) are the output voltage and output current measured under repeated strain. Reprinted with permission from [4], C. Chang, et al., Nano Lett. 10, 726 (2010). () 2010, American Chemical Society. 
leads to size dependent electrical performance change. ${ }^{20,68}$ Therefore, crystallization and structural change under nanoconfinement and size effect are intimately related issues. Considering the many available reviews on the crystallization of polymer materials under confinement, ${ }^{69,70}$ here we focus the discussion on the influence of confined crystallization on the structural characteristics and electrical properties of ferroelectric polymer nanostructures. The situation in ultrathin ferroelectric polymer films is also discussed for comparison. The results about monopolymer PVDF and copolymer P(TrFE-TrFE) will be discussed in Sections 3.1 and 3.2, respectively. Relaxor ferroelectric polymer is a special type of materials that have received intensive interest in recent years. ${ }^{71,72}$ To show to what an extent the nanoconfinement effect may work, the performance change of relaxor ferroelectric polymer under different confinement conditions will also be discussed in Section 3.3.

\subsection{Nanoconfinement Effect in Monopolymer PVDF}

Polymers generally crystallize in the form of thin lamellae where the chains are oriented perpendicular to the lamellar surfaces. The thickness of the lamellae is in the order of nanometer, and their growth is highly altered in nanostructures. For nanostructured ferroelectric polymer, the crystallization confined in one dimensional template, like $\mathrm{AAO}$, is the most typical one. Steinhart et al.$^{42}$ found that nanoconfinement could promote the formation of highly ordered lamellar crystals in PVDF nanotubes obtained by melt-wetting of AAO template with a pore diameter of $400 \mathrm{~nm}$, and the crystal facets with the highest growth rate were oriented parallel to the long axis of the nanotubes. For PVDF nanostructures with cylindrical pores with diameters in the range of 20 to $200 \mathrm{~nm}$ fabricated by the same method, a similar confinement induced preferential orientation along the pore axis was also observed for the $\alpha$-phase polymorph. Preferentially oriented lattice under confined geometry is always observed by many studies, and it seems to be a common feature for polymer materials as a consequence of the anisotropic growth under nanoconfinement. ${ }^{73,74}$

As discussed in the forgoing section, although PVDF usually forms nonferroelectric phase, arrays of isolated PVDF ferroelectric $\gamma$-type nanorods containing oriented lamellar grains supported within a nonpolar $\alpha$-phase film have been fabricated from the AAO template under confined conditions. ${ }^{43}$ As shown in Figure 7, the phase transition can be clearly seen from the X-ray diffraction signal intensity of $\gamma$-phase at different locations. Nanoconfinement induced ferroelectric $\beta$-phase PVDF structure has also been observed by Cauda et al..$^{55}$ and an evident piezoelectric response (without poling or stretching treatment) was obtained for PVDF nanowires with a diameter of only $\sim 5 \mathrm{~nm}$. These findings indicate that confinement at the nanometer scale can induce nonferroelectric to ferroelectric phase transition even without applying stress or strong electric field. Actually, such a confinement induced phase change is not limited only to nanostructures. It was found that in melt recrystallized $30 \mathrm{~nm}$ thick ultrathin PVDF film, confinement with surface-energy controlled metal top layers promotes the formation of ferroelectric $\gamma$ crystals consisting of twisted lamellae. ${ }^{75}$ Micropatterns of ferroelectric $\gamma$-phase PVDF domains isolated by paraelectric $\alpha$-phase domains were developed by employing pre-patterned confinement layers, whose potential application in non-volatile memories were also demonstrated by capacitor and transistor-type memory units. Concerning the degree of macromolecular packing order, both increased and decreased crystallnity have been reported. It was found that wetting of the porous templates by PVDF melts yielded nanotubes with a pronounced crystallinity whereas solution-wetting resulted in the formation of largely amorphous nanotubes. ${ }^{42}$ While it seems that in most cases inhibited crystallization was observed, which may be resulted from the significantly reduced mobility of the macromolecular chains under confined geometry or from the change in nucleation mechanisms. ${ }^{76-78}$

About the crystallization dynamics of PVDF nanostructures, Hilczer et al. found that the relaxation rates of segmental motions in the amorphous phase were shorter in confined geometry than in the bulk, and this difference decreased with increasing temperature. ${ }^{47}$ The relaxation of local mode was broadened due to inhomogeneous relaxation times in the pores. The authors attributed these phenomena to the competition between the surface effect and real nanoconfinement effect. Similar results about the counterbalance between nanoconfinement and interfacial interactions in controlling the crystallization dynamic was also proposed by Martin et al. ${ }^{70}$

Nanoconfinement effect is not only limited to nanostructured PVDF. It is also important in thin films but may lead to somewhat different phenomena. For PVDF films in energy storage application, the coupling interactions among ferroelectric domains were found to be dependent on grain size. A large crystallite size caused strong coupling and impeded dipole reversal, leading to an undesirable antiferroelectric-like state. Instead, the domain coupling was weakened in nanoscale crystallites. ${ }^{79}$ Similar confinement effect was also observed for layered films of PVDF and polycarbonate (PC) fabricated by coextrusion. The nonuniform electric field distribution in the layered structure binds most of the movable charges within the PVDF layers. As the layer thickness decreases to nanometer scale, the charge movement is impeded, resulting in significantly reduced dielectric losses with still a high energy density. ${ }^{80}$

\subsection{Nanoconfinement Effect in Copolymer P(VDF-TrFE)}

In contrast to PVDF, the copolymer $\mathrm{P}(\mathrm{VDF}-\mathrm{TrFE})$ can spontaneously forms the ferroelectric phase, although 

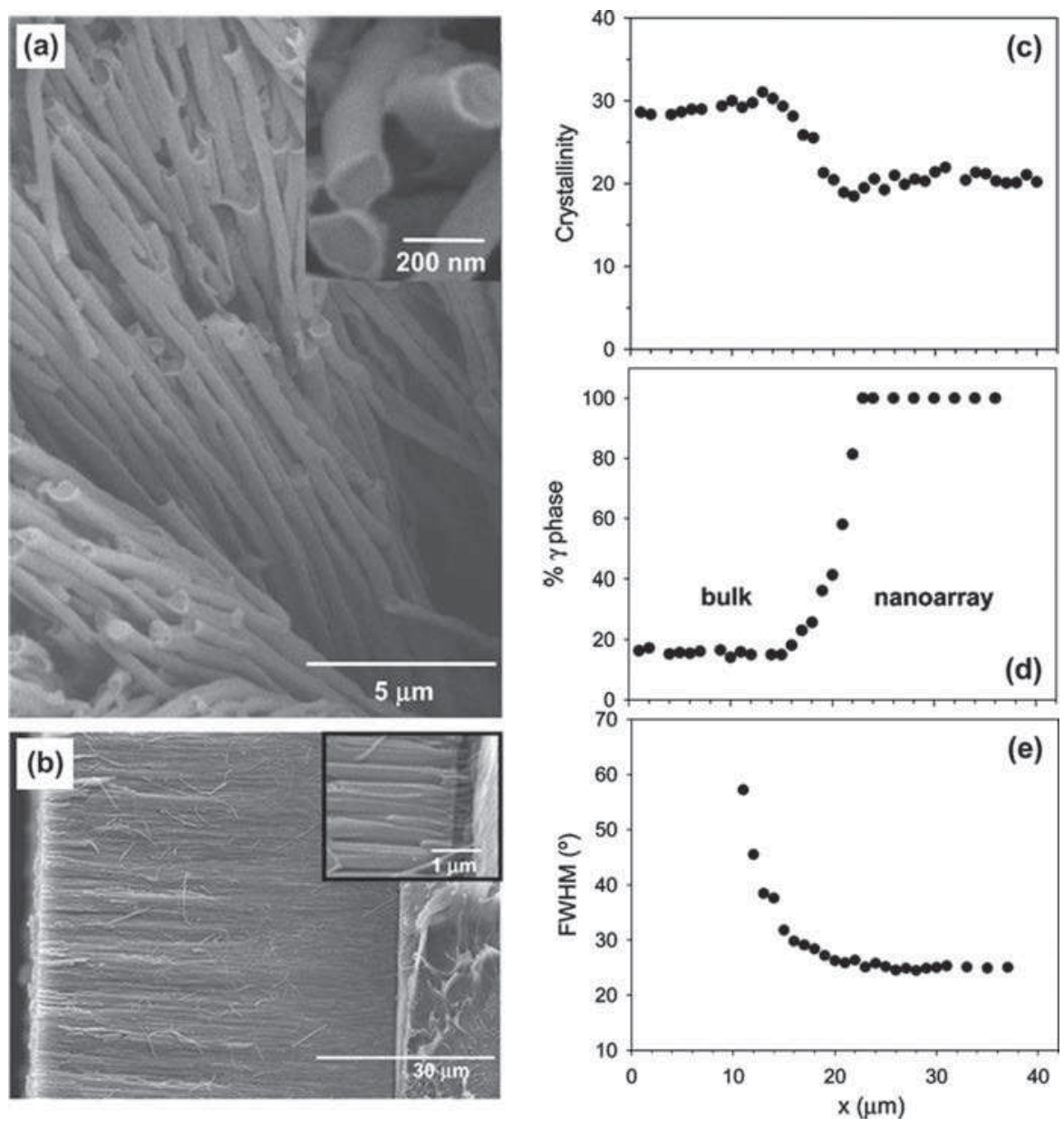

Figure 7. (a) SEM images showing the side and top (inset) views of the PVDF nanorod morphology; (b) cross section of a fractured sample, the inset is a magnified image of the interface between the residual PVDF film (right) and the nanorod array (left); (c) Spatial evolution of degree of crystallinity from the residual polymer film (bulk) to the nanorod array; (d) Spatial evolution of the $\gamma$-phase fraction; (e) FWHM of the 020 reflection indicating the improved orientation. Adapted with permission from [43], M. C. Garcia-Gutierrez, et al., Nano Lett. 10, 1472 (2010). () 2010, American Chemical Society.

the paraelectric phase may also appears. So far most studies about the confinement effect in the copolymer have been focused on its thin films (generally referred to as 'finite size effect'), whose ferroelectricity generally drops markedly when the thickness is less than 50-100 nm..$^{20,67,81-83}$ In $\mathrm{P}(\mathrm{VDF}-\mathrm{TrFE})$ nanostructures, however, the size dependent ferroelectric or piezoelectric performance is rather different and by far less investigated.

For P(VDF-TrFE) nanorods confined within AAO templates, significant deviation from bulk behavior was observed when the pore diameter is less than $40 \mathrm{~nm}$, and nanoconfinement was found to be able to largely enhance the formation of ferroelectric phase (as similar to the phenomena in PVDF), which was explained by the high molecule packing density of the ferroelectric phase oriented crystallization under confinement geometry. ${ }^{50}$ Consequently, a better piezoelectric response was expected, and the melting temperature of the nanorods also decreased with decreasing pore diameter. Investigation on the formation of $\mathrm{P}(\mathrm{VDF}-\mathrm{TrFE})$ nanostructures via melt wetting of AAO template indicated that, cystallization within the template during cooling led to the transition of highly oriented paraelectric phase to ferroelectric phase with a lower degree of orientation. In the final sample the chains are preferentially oriented perpendicular to the long axis of the nanopores, and the size of the crystalline domains is also restricted by the nanopores. ${ }^{49} \mathrm{P}(\mathrm{VDF}-\mathrm{TrFE})$ nanostructures consisting of nanorod arrays and residual film fabricated by solution wetting of AAO template have been studied by using scanning X-ray microdiffraction with synchrotron light. A spatial evolution of polymorphs from a mixture of paraelectric and ferroelectric crystals in the film to a pure ferroelectric phase nanorod arrays was observed. In contrast, only 
ferroelectric phase was obtained in the whole structure fabricated by melt wetting of AAO. A decreased macromolecular packing order under nanoconfinement caused a crystallinity distribution gradient. ${ }^{84}$

Advantageous nanoconfinement effect has also been demonstrated by using prototype sensors. ${ }^{48}$ By comparing the structure and electromechanical characteristics of onedimensional nanowires in 200-nm channel AAO and two dimensional films of $\mathrm{P}(\mathrm{VDF}-\mathrm{TrFE})$ without electric poling, Canavese et al. observed improved piezoelectric response under nanoconfinement. Furthermore, they fabricated flexible tactile sensors and bendable energy harvesters using different polymeric structures and showed that the nanowire sample under confined conditions could generate higher amount of charge compared to that of the thin film sample. The improved sensitivity was attributed to the better spatial arrangement of macromolecular chains, the enhanced $\beta$ crystalline structure with the favorable orientation of the polarization axis under nanoconfinement.

For one dimensional grating $\mathrm{P}(\mathrm{VDF}-\mathrm{TrFE})$ nanostructure with a depth of $120 \mathrm{~nm}$ and a width of $120 \mathrm{~nm}$ fabricated by NIL, it was found that the confinement imposed by the wall trenches of the grating promoted the formation of smaller edge-on oriented lamellar crystals, resulting in ferroelectric domains with a size of one order of magnitude smaller compared to those of the domains in two dimensional films. In such a grating nanostructure the problem caused by uncontrolled large extension of ferroelectric signal over needlelike crystals in films was expected to be resolved, and a large information density of about $0.5 \mathrm{~T}$ bit per in Ref. [2] was calculated. ${ }^{85}$ Another report on $\mathrm{P}(\mathrm{VDF}-\mathrm{TrFE})$ nanocells with a thickness of

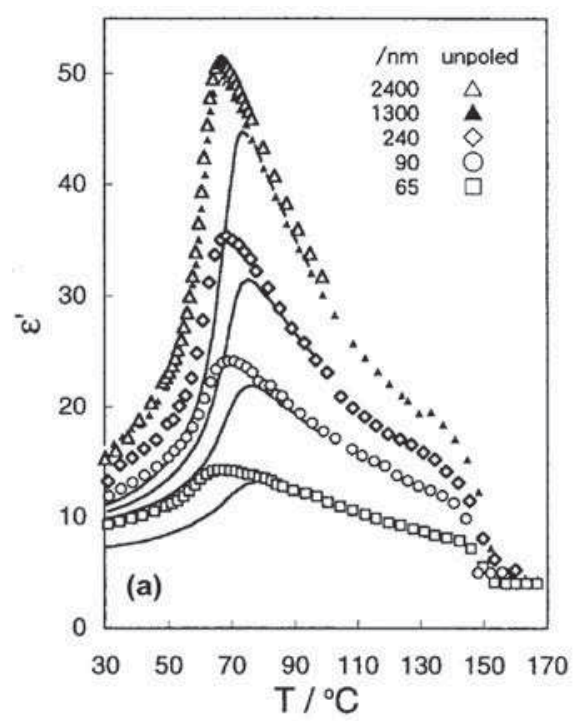

$\sim 80 \mathrm{~nm}$ fabricated by NIL indicated that, when the mold cavities were narrow and deep enough so that the crystallization propagation in the isolated nanocells was prevented, the molecular backbones were preferentially oriented parallel relative to the substrate. ${ }^{37}$ Such a 'complete confinement' was considered to be responsible for the improved ferroelectric performance, as revealed by the loops shown in Figure 1(b). Also, obvious ferroelectricity in $\mathrm{P}(\mathrm{VDF}-\mathrm{TrFE})$ nanotubes with a wall thickness of a few tens of nanometers has been observed. ${ }^{46}$ For the $\mathrm{P}(\mathrm{VDF}-\mathrm{TrFE})$ copolymer 'nanograss' structure with a further decreased lateral size of around $20 \mathrm{~nm}$ mentioned in the Subsection 2.2.2, ${ }^{54}$ a piezoelectricity about several times larger than that of the flat film as evaluated by PFM amplitude signal was reported.

\subsection{Discussion of the Common Features Under Nanoconfinement}

For ease of comparison, a summary of the structural characteristics and property change under confinement of various nanostructures (ultrathin films) of the two typical ferroelectric polymers fabricated by different approaches is given in Table I. From the many results it seems that, despite the inhibited crystallization, nanoconfinement can improve the ferroelectric performance in the P(VDFTrFE). Therefore, several common features may be generalized for the ferroelectric polymers:

(1) nanoconfinement usually leads to preferential orientation of the polymer chains, although the crystallization may be inhibited;

(2) nanoconfinement may promote the formation of ferroelectric phase in both the monopolymer and copolymer;

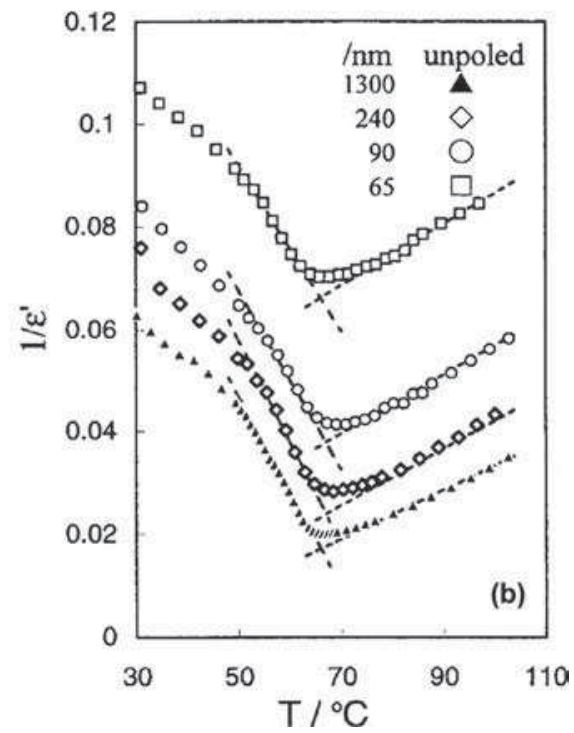

Figure 8. (a) Temperature dependence of the real part of the linear dielectric constant $\varepsilon^{\prime}$ for unpoled and poled P(VDF-TrFE) layers with different thicknesses, where the solid lines represent the data of the poled samples; (b) Curie plots for unpoled P(VDF-TrFE) layers; the $T_{c}$ for each sample can be estimated from the intersection of the two straight dashed lines. Adapted with permission from [86], Urayama, et al., Macromolecules. 33 , 8269 (2000). () 2000, American Chemical Society. 
Table I. Summary of the structural characteristics and property change under confinement of nanostructures (ultrathin films) of the two polymers fabricated by different approaches.

\begin{tabular}{|c|c|c|c|c|c|}
\hline Material & Fabrication approach & Feature size & Structural change & $T_{c}$ change & Refs. \\
\hline PVDF film & & $\sim 100 \mathrm{~nm}$ (thickness) & $\alpha$-to $\gamma$-phase & & [35] \\
\hline PVDF nanotubes & AAO template & $\sim 400 \mathrm{~nm}$ (diameter) & Improved crystallinity & & [42] \\
\hline PVDF nanorods & AAO template & $150-200 \mathrm{~nm}$ (diameter) & $\alpha$-to $\gamma$-phase & & {$[43,84]$} \\
\hline PVDF nanorods & AAO template & 20-200 nm (diameter) & Reduced crystallinity & & {$[47]$} \\
\hline PVDF nanowires & $\begin{array}{l}\text { Mesoporous silica in } \\
\text { AAO }\end{array}$ & $\sim 5-10 \mathrm{~nm}$ (diameter) & $\alpha$-to $\beta$-phase & & [55] \\
\hline PVDF film & & $30 \mathrm{~nm}$ (thickness) & $\alpha$-to $\gamma$-phase & & {$[75]$} \\
\hline $\begin{array}{l}\mathrm{P}(\mathrm{VDF}-\mathrm{TrFE}) \text { nanocell } \\
\text { arrays and nanogratings }\end{array}$ & Microimprinting & $\sim 2 \mu \mathrm{m}$ (width) & & & {$[36]$} \\
\hline $\begin{array}{l}\mathrm{P}(\mathrm{VDF}-\mathrm{TrFE}) \text { nanocell } \\
\text { arrays }\end{array}$ & NIL & $\begin{array}{l}80 \mathrm{~nm} \text { (height) } \times 140 \mathrm{~nm} \\
\text { (width) }\end{array}$ & Improved crystallinity & & {$[37]$} \\
\hline $\mathrm{P}(\mathrm{VDF}-\mathrm{TrFE})$ regular arrays & NIL & $\sim 139 \mathrm{~nm}$ (width) & & & {$[38]$} \\
\hline $\mathrm{P}(\mathrm{VDF}-\mathrm{TrFE})$ nanowires & AAO template & 55-360 nm (diameter) & & & {$[44]$} \\
\hline $\mathrm{P}(\mathrm{VDF}-\mathrm{TrFE})$ nanotubes & AAO template & 250-300 nm (diameter) & & & {$[45]$} \\
\hline $\begin{array}{l}\mathrm{P}(\mathrm{VDF}-\mathrm{TrFE}) \text { nanotubes and } \\
\text { composite nanotubes }\end{array}$ & AAO template & $50-150 \mathrm{~nm}$ (diameter) & Reduced crystallinity & & [46] \\
\hline $\mathrm{P}(\mathrm{VDF}-\mathrm{TrFE})$ nanowires & AAO template & $\sim 200 \mathrm{~nm}$ (diameter) & Improved crystallinity & & [48] \\
\hline $\begin{array}{l}\mathrm{P}(\mathrm{VDF}-\mathrm{TrFE}) \text { nanorods and } \\
\text { nanotubes }\end{array}$ & AAO template & $35-400 \mathrm{~nm}$ (diameter) & Reduced crystallinity & Unaltered & [49] \\
\hline $\mathrm{P}(\mathrm{VDF}-\mathrm{TrFE})$ nanorods & AAO template & $15-200 \mathrm{~nm}$ (diameter) & Improved crystallinity & Unaltered & {$[50]$} \\
\hline $\mathrm{P}(\mathrm{VDF}-\mathrm{TrFE})$ nanorods & $\mathrm{SiO}_{2}$ template & $\sim 120 \mathrm{~nm}$ (diameter) & $\begin{array}{l}\text { Improved alignment } \\
\text { order }\end{array}$ & & [53] \\
\hline $\mathrm{P}(\mathrm{VDF}-\mathrm{TrFE})$ 'nanograss' & Si nanograss template & $\sim 20 \mathrm{~nm}$ (diameter) & & & {$[54]$} \\
\hline $\mathrm{P}(\mathrm{VDF}-\mathrm{TrFE})$ nanograting & NIL & $\begin{array}{l}120 \mathrm{~nm}(\text { depth }) \times 120 \mathrm{~nm} \\
\quad(\text { width })\end{array}$ & $\begin{array}{l}\text { Reduced domain size } \\
\text { with better orientation }\end{array}$ & & {$[85]$} \\
\hline $\mathrm{P}(\mathrm{VDF}-\mathrm{TrFE})$ thin films & & $\begin{array}{l}65 \mathrm{~nm}-2.4 \mu \mathrm{m} \\
\quad \text { (thickness) }\end{array}$ & Reduced crystallinity & Unaltered & [86] \\
\hline $\mathrm{P}(\mathrm{VDF}-\mathrm{TrFE})$ nanorods & AAO template & $<200 \mathrm{~nm}$ (diameter) & & Decreased & [87] \\
\hline
\end{tabular}

(3) due to the improved orientation and ferroelectric phase formation, nanoconfinement may improve the ferroelectricity or piezoelectric response along the molecular dipole alignment direction even at the scale of several tens of nanometers.

Thus, it seems reasonable to conclude that, in contrast to the normal undesirable size effect in ferroelectric polymer thin films with deteriorated ferroelectricity, confinement effect in nanostructures of the polymers may be utilized to improve the performance of the relevant devices.

In the aforementioned 3 features, the oriented growth under nanoconfinement is similar to that observed in many other polymers, and may be attributed to the change in nucleation mechanism, etc. The most intriguing feature for this special type of polymer seems to be the enhanced formation of the ferroelectric phase. The reason is still not clarified in the limited publications. Here we tentatively give two possible reasons: molecular packing density and counterbalance of the molecular interactions. First, both the ferroelectric $\beta$-phase (all-trans TT conformation) and $\gamma$-phase (combined $T_{3} G_{3} G^{\prime}$ conformation) of the monopolymer and copolymer have a higher packing density than that of the $\alpha$-phase (alternating trans-gauche TGTG' conformation), ${ }^{17,50,88-90}$ and as a consequence, the ferroelectric phase are formed under nanoconfinement so as to reduce the free energy (steric interaction) of the system. Second, it has been reported that polar solvent, such as $N, N^{\prime}$-dimethylformamide ${ }^{91}$ or $N, N^{\prime}$ dimethylacetamide, ${ }^{92}$ can increase the chain mobility of PVDF due to the disrupted inter-chain interaction, which in turn can promote its crystallization into the polar $\beta$ phase. We may assume that the confining surface works in a similar way, which may disrupt the chain interaction and promote the formation of polar $\beta$ or $\gamma$-phase. Actually, the chemical nature of surface may play an important role for the crystallization of thin films. ${ }^{93,94}$ Detailed research on both the kinetical and thermodynamical aspects of crystallization under nanoconfinement for this type of polymer is necessary to elucidate the details. ${ }^{95}$

\subsection{Performance of Other Ferroelectric Polymers Under Nanoconfinement}

Relaxor ferroelectric polymer is a special type of ferroelectric polymer that is formed by introducing defects into the normal ferroelectric copolymer P(VDF-TrFE) via high energy irradiation or copolymerization with another monomer so as to form a terpolymer, such as poly(vinylidene fluoride-co-trifluoroethylene-co-chlorotrifluoroethylene) P(VDF-TrFE-CFE) or its derivatives. ${ }^{96-99}$ In addition to the broad dielectric peak that shifts to higher temperature with frequency as observed in inorganic ferroelectrics, relaxor polymer shows giant electrostrictive response, very large dielectric constant and electro-optic effect, ${ }^{96-99}$ making them promising 
for actuation, electric energy storage and electro-optics applications. Although specific nanostructures are not necessary for these applications, the nanoconfinement induced properties may still be utilized for designing new relaxor polymer system. Poly(vinylidene fluoride-cotrifluoroethylene-co-chlorotrifluoroethylene)-graft-polystyrene $[\mathrm{P}(\mathrm{VDF}-\mathrm{TrFE}-\mathrm{CTFE})-\mathrm{g}-\mathrm{PS}]$ is such a system. It was found that after crystallization-induced microphase separation, the PS side chains were segregated to the periphery of $\mathrm{P}(\mathrm{VDF}-\mathrm{TrFE})$ crystals, forming a nanoscale interfacial confining layer. The low polarizability of this confining layer causes a weaker local polarization field than the depolarization field, which in turn leads to fast dipole reversal and an antiferroelectric-like behavior with improved electric energy storage performance with low loss. ${ }^{100}$

\section{INFLUENCE OF NANOCONFINEMENT ON THE CURIE TRANSITION AND POLARIZATION SWITCHING BEHAVIORS}

Concerning the Curie temperature $T_{c}$ of the ferroelectric copolymer nanostructures, in the limited papers published on this matter, both unaltered and depressed $T_{c}$ as compared to that of bulk material have been observed (see Table I). ${ }^{49,50,86,87}$ Temperature dependence of permittivity has been measured for 2 dimensional thin films with a wide range of thickness from $65 \mathrm{~nm}$ to $2.4 \mu \mathrm{m}$. As the example shown in Figure $8,{ }^{86}$ the results reveal a rather constant $T_{c}$. Investigations on $\mathrm{P}(\mathrm{VDF}-\mathrm{TrFE})$ nanorods in AAO pores indicate a suppression of the bulk ferroelectric transition upon heating and a lower $T_{c}$ upon cooling, which is revealed by the temperature dependence of first derivative of permittivity as shown in Figure $9 .{ }^{87}$ Shingne
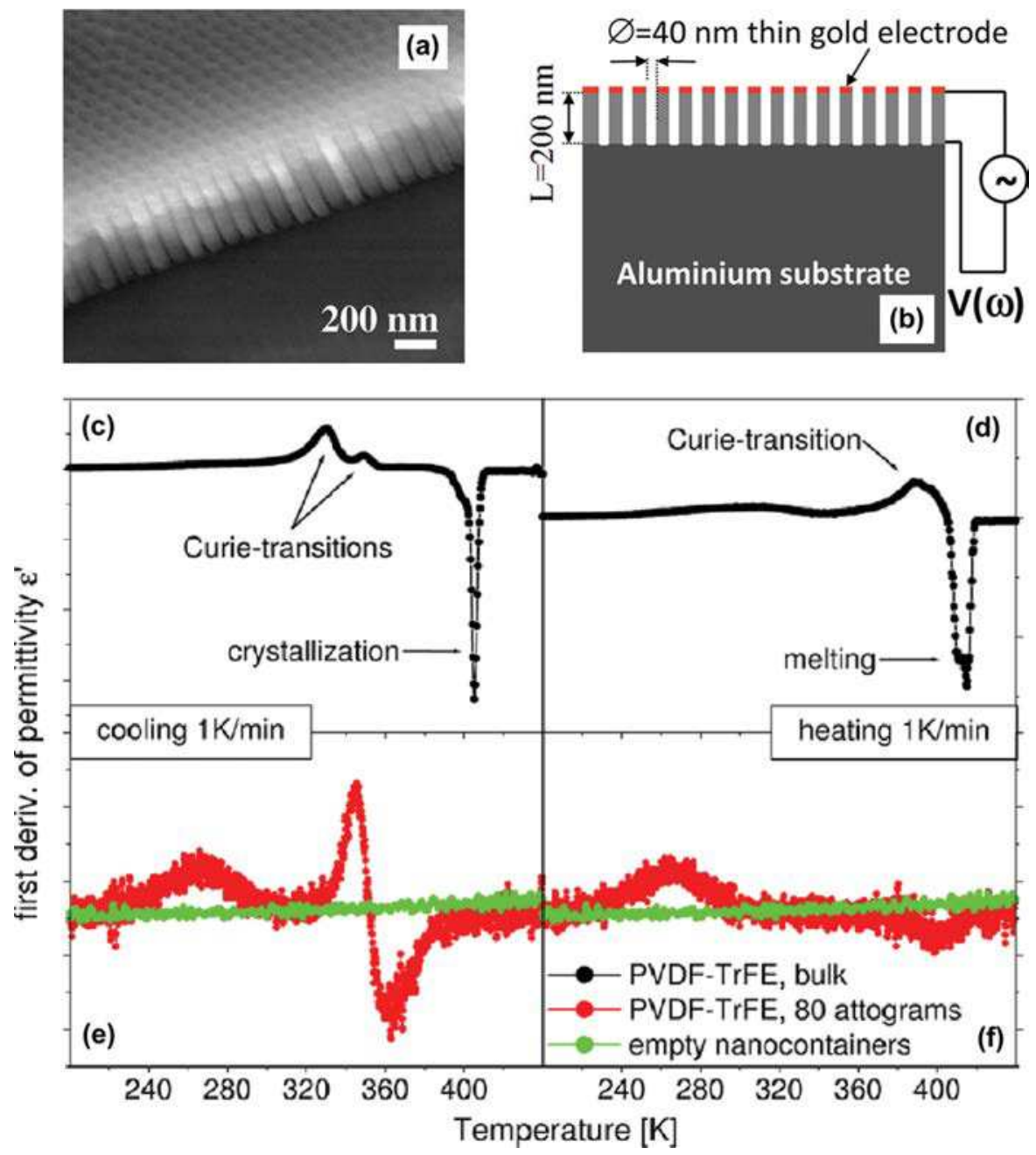

Figure 9. (a) SEM image of the AAO pore containers; (b) Schematic representation of the sample cell for electric measurement, where the electrodes are connected to a dielectric spectrometer; (c)-(f) First derivative of permittivity measured upon cooling (c), (e) and heating (d), (f) for P(VDF-TrFE) in the bulk (black), for 80 attograms of $\mathrm{P}(\mathrm{VDF}-\mathrm{TrFE})$ per nanocontainer (red), and for the empty nanocontainers (green). Adapted with permission from [87], A. Serghei, et al., Nano Lett. 13, 577 (2013). (C) 2013, American Chemical Society. 

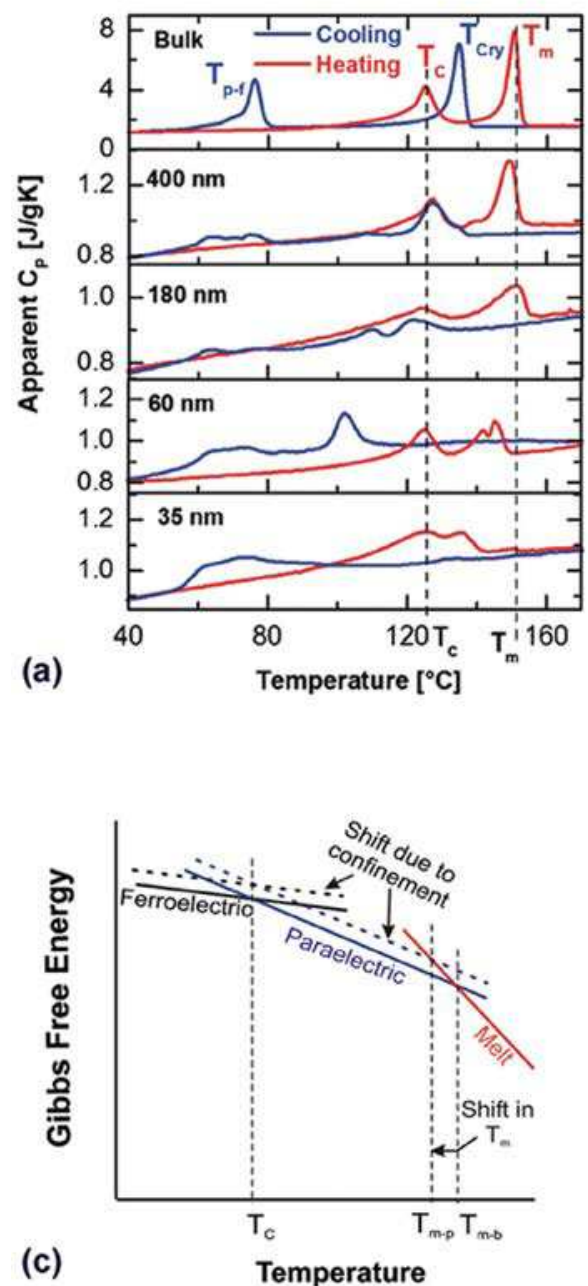
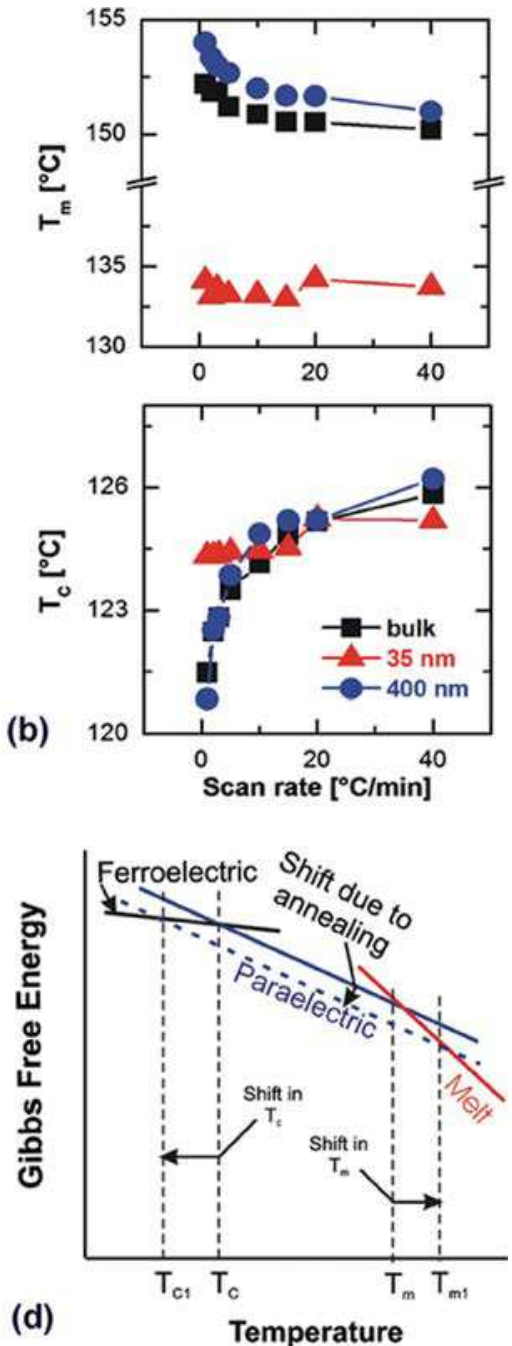

Figure 10. (a) DSC heating and cooling scans for P(VDF-TrFE) bulk material and nanostructures with different diameters; (b) Melting temperature $\left(T_{m}\right)$ and $T_{c}$ for various samples measured during heating after cooling with different scan rates; (c) Schematic of the Gibbs free energy for ferroelectric, para electric and melt phase, where the increase in the Gibbs free energy due to confinement is shown by the dashed lines $\left(T_{m-b}\right.$ : melting temperature of bulk, $T_{m-p}$ : melting temperature in pores, $T_{c}$ : Curie temperature); (d) free energy diagram of the ferroelectric, paraelectric and melt phases of $\mathrm{P}(\mathrm{VDF}-\mathrm{TrFE})$, where the dashed line shows the shift due to annealing in the paraelectric phase. Adapted with permission from [49], N. Shingne, et al., Polymer 54, 2737 (2013). (C) 2013, Elsevier B.V.

et al. carefully investigated the phase diagram of both $\mathrm{P}(\mathrm{VDF}-\mathrm{TrFE})$ bulk material and nanostructures of various feature sizes fabricated by AAO template using differential scanning calorimetry (DSC). ${ }^{49}$ As shown in Figure 10(a), during cooling, the ferroelectric to paraelectric transition temperature $T_{p-f}$ covers a broad temperature range both in the bulk and in the nanostructures. During heating, the clear peak indicative of $T_{c}$ remains basically unaffected by nanoconfinement, although the $T_{m}$ was changed. This observation was explained by the similar influence of nanoconfinement on the stability of ferroelectric and the paraelectric phases as illustrated in Figure 10(b). Concerning the annealing effect (Fig. 10(c)), with decreasing cooling rate $T_{c}$ decreases and $T_{m}$ increases for bulk and nanostructures with a feature size of $400 \mathrm{~nm}$ as a consequence of the shifted free energy of the paraelectric phase (Fig. 10(d)). For the nanostructure with a diameter of $35 \mathrm{~nm}$, however, the annealing effect is absent due to the inhibited crystallization under confinement.

As for the transition character, both bulk type ferroelectric transition and different confining interface induced second-order type ferroelectric transition was observed.$^{50}$ In addition, the polarization switching process in copolymer nanomesa has also been studied by high resolution PFM. ${ }^{101}$ A 'Remote domain nucleation' phenomenon and spatially nonuniform wall velocity have been observed, which were related to a random-bond type disorder associated with defects. This further reveals that 
nanoconfinement may lead to switching behaviors that are quite different from those of bulk ferroelectric polymers.

\section{SUMMARY}

Nanostructured ferroelectric polymer materials have attracted intensive research interest in recent years due to their great potential in a wide range of applications, particularly in new organic devices. In this article the techniques that have been used for fabricating ferroelectric polymer nanostructures over the last decade are briefly reviewed. More importantly, the nanoconfinement induced structural change, its influence on the physical properties of the ferrelectric polymer nanostructures as well as the possible mechanisms are discussed. Among the techniques, the 'top-down' NIL and the 'bottom-up' AAO template synthesis are the two most promising ones that are capable of generating ordered ferroelectric polymer nanoscale patterns. However, challenges still remain on how to achieve higher spatial resolution and better control over microstructure (degree of order and desirable orientation) and performance. Concerning the simple template free self organization method, problems like poor control over size and distribution and irregular morphology of the nanostructures still need to be resolved. The limited existing publications indicate that nanoconfinement may induce preferential molecular orientation, promote the formation of polar ferroelectric phase, and these in turn may give rise to improved but not deteriorated ferroelectricity or piezoelectric response. The structure change may be attributed to the modified inter-chain interactions or their interactions with the confining surface. A deep understanding of the detailed mechanisms underlying the microstructure and performance evolution under nanoconfinement is a prerequisite for future development of the relevant devices.

Acknowledgments: This work was supported by the 'Hundred Talents Program' of Chinese Academy of Sciences, the National key Basic Research Program of China (973 Program) under Grant No. 2013CB632900, and the National Science Foundation of China under Grant No. 11074277.

\section{References and Notes}

1. S. B. Lang and S. Muensit, Appl. Phys. A Mater. Sci. Process. 85,125 (2006).

2. A. D. Handoko and G. K. L. Goh, Sci. Adv. Mat. 2, 16 (2010).

3. R. C. G. Naber, C. Tanase, P. W. M. Blom, G. H. Gelinck, A. W. Marsman, F. J. Touwslager, S. Setayesh, and D. M. De Leeuw, Nature Mater. 4, 243 (2005).

4. C. Chang, V. H. Tran, J. Wang, Y. K. Fuh, and L. Lin, Nano Lett. 10, 726 (2010).

5. S. Priya, J. Electroceram. 19, 167 (2007).

6. C. S. Jung, L. T. Lee, P. W. Jang, K. Seomoon, and K. H. Kim, J. Nanosci. Nanotechnol. 12, 3326 (2012).

7. J. Zhang, A. A. Heitmann, S. P. Alpay, and G. A. Rossetti, Integr. Ferroelectr. 125, 168 (2011)
8. C. S. Jung, L. T. Lee, P. W. Jang, K. Seomoon, and K. H. Kim, J. Nanosci. Nanotechnol. 12, 3326 (2012).

9. P. F. Liu, J. L. Wang, X. J. Meng, J. Yang, B. Dkhil, and J. H. Chu, New J. Phys. 12, 023035 (2010).

10. N. Setter and R. Waser, Acta Mater. 48, 151 (2000).

11. H. S. Nalwa, J. Macromol. Sci. Part C Polymer Reviews 31, 341 (1991).

12. Y. Takase, J. W. Lee, J. I. Scheinbeim, and B. A. Newman, Macromolecules 24, 6644 (1991)

13. J. Su, Z. Y. Ma, J. I. Scheinbeim, and B. A. Newman, J. Polym. Sci. B 33, 85 (1995).

14. L. Yongjin, H. Shimizu, and T. Furumichi, J. Polym. Sci. B Polym. Phys. 45, 2707 (2007).

15. S. Horiuchi and Y. Tokura, Nat. Mater. 7, 357 (2008).

16. A. J. Lovinger, Science 220, 4602 (1983).

17. H. S. Nalwa (ed.), Ferroelectric Polymers: Chemistry, Physics and Applications, Marcel Dekker, New York (1995)

18. D. Guo, X. Chen, X. Chu, F. Zeng, Y. Bai, J. Cao, and B. Dkhil, J. Appl. Phys. 113, 187210 (2013).

19. R. L. Jones, S. K. Kumar, D. L. Ho, R. M. Briber, and T. P. Russell, Nature (London) 400, 146 (1999).

20. H. Kliem and R. Tadros-Morgane, J. Phys. D: Appl. Phys. 38, 1860 (2005).

21. D. Guo, I. Stolichnov, and N. Setter, J. Phys. Chem. B 115, 13455 (2011)

22. D. B. Li and D. A. Bonnell. Annu. Rev. Mater. Res. 38, 351 (2008).

23. Y. B.Yuan, T. J. Reece, P. Sharma, S. Poddar, S. Ducharme, A. Gruverman, Y. Yang, and J. S. Huang, Nat. Mater.10, 296 (2011).

24. X. Qiu, J. Appl. Phys. 108, 011101 (2010).

25. J. Varghese, R. W. Whatmore, and J. D. Holmes, J. Mater. Chem. C 1, 2618 (2013).

26. M. Lazzari, C. Rodriguez-Abreu, and J. Rivas, J. Nanosci. Nanotechnol. 6, 892 (2006).

27. V. V. Kislyuk and O. P. Dimitriev, J. Nanosci. Nanotechnol. 8, 131 (2008).

28. N. Fukutake, N. Miyoshi, Y. Takasawa, T. Urakawa, T. Gowa, K. Okamoto, A. Oshima, S. Tagawa, and M. Washio, Jpn. J. Appl. Phys. 49, 065201 (2010).

29. H. M. Manohara, E. Morikawa, J. Choi, and P. T. Sprunger, J. Microelectromech. S. 8, 417 (1999).

30. J. Choi, H. M. Manohara, E. Morikawa, P. T. Sprunger, P. A. Dowben, and S. P. Palto, Appl. Phys. Lett. 76, 381 (2000).

31. Y. J. Kim, J. S. Hwan, and S. Y. Park, J. Nano. Sic. Nanotechnol. 11, 301 (2011).

32. C. C. Wu, S. L. C. Hsu, and I. L. Lo, J. Nanosci. Nanotechnol. 10, 6446 (2010).

33. S. W. Choi, J. Q. Han, J. Lim, and Jiseok, J. Nanosci. Nanotechnol. 11, 5921 (2011).

34. Z. J. Hu, G. Baralia, and V. Bayot, Nano Lett. 5, 1738, (2005).

35. S. J. Kang, Y. J. Park, J. Y. Hwang, H. Ju. Jeong, J. S. Lee, K. J. Kim, H. C. Kim, J. Huh, and C. Park, Adv. Mater. 19, 581 (2007)

36. L. Zhang, S. Ducharme, and J. Y. Li, Appl. Phys. Lett. 91, 172906 (2007)

37. Z. J. Hu, M. W. Tian, B. Nysten, and A. M. Jonas, Nat. Mater. 8,62 (2009).

38. Y. M. Liu, D. N. Weiss and J. Y. Li, ACS Nano 4, 83 (2010).

39. J. Martín, J. Maiz, J. Sacristan, and C. Mijangos, Polymer 53, 1149 (2012).

40. M. Steinhart, Adv. Polym. Sci. 123, 87 (2008)

41. H. Masuda and K. Fukuda, Science. 268, 1466 (1995).

42. M. Steinhart, S. Senz, R. B. Wehrspohn, U. Golsele, and J. H. Wendorff, Macromolecules 36, 3646 (2003).

43. M. C. Garcia-Gutierrez, A. Linares, J. J. Hernandez, D. R. Rueda, T. A. Ezquerra, P. Poza, and R. J. Davies, Nano Lett. 10, 1472 (2010) 
44. S. T. Lau, R. K. Zheng, H. L. W. Chan, and C. L. Choy, Mater. Lett. 60, 2357 (2006).

45. X. Li, Y. F. Lim, K. Yao, F. E. H. Tay, and K. H. Seah, Phys. Chem. Chem. Phys. 15, 515 (2013).

46. C. C. Wang, Q. D. Shen, S. C. Tang, Q. Wu, H. M. Bao, C. Z. Yang, and X. Q. Jiang, Macromol. Rapid Commun. 29, 724 (2008).

47. B. Hilczer, E. Markiewicz, K. Pogorzelec-Glaser, M. Połomska, and A. Pietraszko, Ferroelectrics 417, 124 (2011).

48. G. Canavese, S. Stassi, V. Cauda, A. Verna, P. Motto, A. Chiodoni, S. L. Marasso, and D. Demarchi, IEEE Sens. J. 13, 2237 (2013).

49. N. Shingne, M. Geuss, B. Hartmann-Azanza, M. Steinhart, and T. Thurn-Albrecht, Polymer 54, 2737 (2013).

50. J. L. Lutkenhaus, K. McEnnis, A. Serghei, and T. P. Russell, Macromolecules 43, 3844 (2010).

51. Y. J. Wu, Q. Z. Gu, G. Z. Ding, F. Q. Tong, Z. J. Hu, and A. M. Jonas, ACS Macro. Lett. 2, 535 (2013).

52. J. H. Lin, S. G. Lu, M. Lin, M. Geu, and Q. M. Zhang, Appl. Phys. Lett. 95, 022911 (2009).

53. S. Oh, Y. Kim, Y. Y. Choi, D. Kim, H. Choi, and K. No, $A d v$. Mater. 24, 5708 (2012).

54. C. C. Hong, S. Y. Huang, J. Shieh, and S. H. Chen, Macromolecules 45, 1580 (2012).

55. V. Cauda, B. Torre, A. Falqui, G. Canavese, S. Stassi, T. Bein, and M. Pizzi, Chem. Mater. 24, 4215 (2012).

56. P. R. Kumar, N. Khan, S. Vivekanandhan, N. Satyanarayana, and A. K. Mohanty, J. Nanosci. Nanotechnol. 12, 1 (2012).

57. D. Mandal, S. Yoon, and K. J. Kim, Macromol. Rapid Commun. 32, 831 (2011).

58. S. Barik, H. H. Tan, J. W. Leung, and C. Jagadish, J. Nanosci. Nanotechnol. 10, 1525 (2010).

59. R. Chapman, M. Danial, M. L. Koh, K. A. Jolliffe, and S. Perrier, Chem. Soc. Rev. 41, 6023 (2012).

60. K. C. Barick and D. Bahadur, J. Nanosci. Nanotechnol. 10, 668 (2010).

61. C. Lu, H. Moehwald, and A. Fery, Soft Mater. 3, 1530 (2007).

62. S. Easwaramoorthi, P. Kim, and J. Lim, J. Mater. Chem. 20, 9684 (2010).

63. W. A. Zhang and A. H. E. Muller, Prog. Polym. Sci. 38, 1121 (2013).

64. J. Y. Li, Q. G. Du, and S. Ducharme, J. Appl. Phys. 104, 094302 (2008).

65. X. S. Chen, X. C. Chu, F. Zeng, J. Huang, and D. Guo, Sci. Adv. Mater. 5, 1 (2013).

66. G. Reiter and G. R. Strobl, Progress in Understanding of Polymer Crystallization, Springer, Berlin (2007).

67. D. Guo and N. Setter, Macromolecules 46, 1883 (2013).

68. H. Schmalz, A. Knoll, and A. J. Muller, Macromolecules 35, 10004 (2002).

69. T. Sakurai, H. Nagakura, S. Gondo, and S. Nojima, Polymer J. 45, 436 (2013).

70. J. Martın, C. Mijangos, A. Sanz, T. A. Ezquerra, and A. Nogales, Macromolecules 42, 5395 (2009).

71. Q. Chen, K. Ren, B. Chu, Y. Liu, Q. M. Zhang, and V. A. Levstik, Ferroelectrics 354, 178 (2007).

72. V. V. Kochervinskii, Crystallogr. Rep. 54, 1146 (2009).
73. H. Wu, Y. Cao, R. Ishige, Y. Higaki, T. Hoshino, N. Ohta, and A. Takahara, Acs Macro. Letters 2, 414 (2013).

74. Y. Kikkawa, H. Abe, M. Fujita, T. Iwata, Y. Inoue, and Y. Doi, Macromol. Chem. Phys. 204, 1822 (2003).

75. S. J. Kang, I. Bae, J. H. Choi, Y. J. Park, P. S. Jo, Y. K., K. J. Kim, J. M. Myoung, E. Kim, and C. Park, J. Mater. Chem. 21, 3619 (2011).

76. B. Vanroy, M. Wubbenhorst, and S. Napolitano, ACS Macro. Lett. 2, 168 (2013).

77. S. Diaham, M. Bechara, M. L. Locatelli, and T. Lebey, J. Appl. Phys. 110, 063703 (2011).

78. J. Maiz, J. Martin, and C. Mijangos, Langmuir 28, 12296 (2012).

79. F. X. Guan, J. Wang, J. L. Pan, Q. Wang, and L. Zhu, Macromolecules 43, 6739 (2010).

80. M. Mackey, D. E. Schuele, L. Zhu, L. Flandin, M. A. Wolak, J. S. Shirk, A. Hiltner, and E. Baer, Macromolecules 45, 1954 (2012).

81. J. L. Keddle, R. A. L. Jones, and R. A. Cory, EuroPhys. Lett. 27, 59 (1994).

82. A. V. Bune, V. M. Fridkin, S. Ducharme, L. M. Blinov, S. P. Palto, A. V. Sorokin, S. G. Yudin, and A. Zlatkin, Nature 391, 874 (1998).

83. R. C. G. Naber and P. W. M. Blom, J. Phys. D: Appl. Phys. 39, 503 (2006).

84. M. C. Garcia-Gutierrez, A. Linares, I. Martin-Fabiani, J. J. Hernandez, M. Soccio, D. R. Rueda, T. A. Ezquerra, and M. Reynolds, Nanoscale 5, 6006 (2013).

85. D. E. Martinez-Tong, M. Soccio, M. C. A. Nogales GarciaGutierrez, D. R. Rueda, N. Alayo, F. Pérez-Murano, and T. A. Ezquerra, Appl. Phys. Lett. 102, 191601 (2013).

86. K. Urayama, M. Tsuji, and D. Neher, Macromolecules 33, 8269 (2000).

87. A. Serghei, W. Zhao, D. Miranda, and T. P. Russell, Nano Lett. 13, 577 (2013).

88. J. B. Lando and W. W. Doll, Macromol. Sci., Part B: Phys. 2, 205 (1968).

89. E. Bellet-Amalric1 and J. F. Legrand, Eur. Phys. J. B 3, 225 (1998).

90. Y. Abe and K. Tashiro, Polymer 42, 3409 (2001).

91. M. Benz, W. B. Euler, and O. J. Gregory, Macromolecules 35, 2682 (2002).

92. W. Ma, J. Zhang, and X. J. Wang, Mater. Sci. 43, 398 (2008).

93. I. Martin-Fabiani, M. C. Garcia-Gutierrez, D. R. Rueda, A. Linares, J. J. Hernandez, T. A. Ezquerra, and M. Reynolds, ACS. Appl. Mater. Interfaces 5, 5324 (2013).

94. R. L. Jones, S. K. Kumar, D. L. Ho, R. M. Briber, and T. P. Russell, Macromolecules 34, 559 (2001).

95. Y. Guan, G. M. Liu, P. Y. Gao, L. Li, G. Q. Ding, and D. J. Wang, ACS Macro. Lett. 2, 181 (2013).

96. Q. M. Zhang, V. Bharti, and X. Zhao, Science 280, 2101 (1998).

97. D. Y. Jeong, Y. K. Wang, M. Huang, Q. M. Zhang, G. J. Kavarnos, and F. Bauer, J. Appl. Phys. 96, 316 (2004).

98. X. Zhou, B. Chu, B. Neese, M. Lin, and Q. M. Zhang, IEEE Trans. Dielectr. Electr. Insul. 14, 1133 (2007).

99. M. Valant, Prog. Mater. Sci. 57, 980 (2012).

100. F. X. Guan, J. Wang, L. Y. Yang, J. K. Tseng, K. Han, Q. Wang, and L. Zhu, Macromolecules 44, 2190 (2011).

101. P. Sharma, J. R. Timothy, S. Ducharme, and G. Alexei, Nano Lett. 11, 1970 (2011).

Received: 12 October 2013. Accepted: 10 December 2013. 